University of New Hampshire

University of New Hampshire Scholars' Repository

$12-1-2000$

\title{
Thermosensitivity of the lobster, Homarus americanus, as determined by cardiac assay
}

Winsor H. Watson III

University of New Hampshire, Durham, win.watson@unh.edu

Steven $\mathrm{H}$. Jury

University of New Hampshire, Durham

Follow this and additional works at: https://scholars.unh.edu/jel

\section{Recommended Citation}

Jury, S. H. and W. H. Watson III. 2000. Thermosensitivity of the American lobster, Homarus americanus.

Biol. Bull. 199: 257-264. https://doi.org/10.2307/1543182

This Article is brought to you for free and open access by the Institute for the Study of Earth, Oceans, and Space (EOS) at University of New Hampshire Scholars' Repository. It has been accepted for inclusion in Jackson Estuarine Laboratory by an authorized administrator of University of New Hampshire Scholars' Repository. For more information, please contact Scholarly.Communication@unh.edu. 


\title{
Thermosensitivity of the Lobster, Homarus americanus, as Determined by Cardiac Assay
}

\author{
STEVEN H. JURY* AND WINSOR H. WATSON III \\ Zoology Department and Center for Marine Biology, University of New Hampshire, \\ Durham, New Hampshire 03824
}

\begin{abstract}
It is generally accepted that crustaceans detect, and respond to, changes in water temperature, yet few studies have directly addressed their thermosensitivity. In this investigation a cardiac assay was used as an indicator that lobsters (Homarus americanus) sensed a change in temperature. The typical cardiac response of lobsters to a 1-min application of a thermal stimulus, either warmer $(n=$ $19)$ or colder $(n=17)$ than the holding temperature of 15 ${ }^{\circ} \mathrm{C}$, consisted of a short bradycardia $(39.5 \pm 8.0 \mathrm{~s})$ followed by a prolonged tachycardia $(188.2 \pm 10.7 \mathrm{~s})$. Lobsters exposed to a range of rates of temperature change $(0.7,1.4$, 2.6, $5.0{ }^{\circ} \mathrm{C} / \mathrm{min}$ ) responded in a dose-dependent manner, with fewer lobsters responding at slower rates of temperature change. The location of temperature receptors could not be determined, but lesioning of the cardioregulatory nerves eliminated the cardiac response. Although the absolute detection threshold is not known, it is conservatively estimated that lobsters can detect temperature changes of greater than $1{ }^{\circ} \mathrm{C}$, and probably as small as $0.15{ }^{\circ} \mathrm{C}$. A comparison of winter and summer lobsters, both held at 15 ${ }^{\circ} \mathrm{C}$ for more than 4 weeks, revealed that although their responses to temperature changes were similar, winter lobsters $(n=18)$ had a significantly lower baseline heart rate $(34.8 \pm 4.4 \mathrm{bpm})$ and a shorter duration cardiac response (174 s) than summer lobsters $(n=18 ; 49.9 \pm 5.0 \mathrm{bpm}$, and $320 \mathrm{~s}$ respectively). This suggests that some temperatureindependent seasonal modulation of cardiac activity may be occurring.
\end{abstract}

Received 22 March 1999; accepted 14 August 2000.

*Present address: Caribbean Marine Research Center, Tequesta, FL 33469. E-mail: sjury@cmrc.org

\section{Introduction}

Temperature is one of the most important and pervasive environmental influences on the American lobster, Homarus americanus (Cobb and Phillips, 1980; Aiken and Waddy, 1986; Factor, 1995). It is generally accepted that locomotory activity in this species is temperature dependent (McLeese and Wilder, 1958; Reynolds and Casterlin, 1979; Haakonsen and Anoruo, 1994) and that it carries out seasonal inshore to offshore migrations to gain the developmental benefits of warmer coastal temperatures in the spring and summer (Cooper and Uzmann, 1971; Pezzack and Duggan, 1986; Karnofsky et al., 1989; Haakonsen and Anoruo, 1994; Factor, 1995; Watson et al., 1999). Laboratory studies have demonstrated that $H$. americanus has a thermal preference of about $16^{\circ} \mathrm{C}$ (Reynolds and Casterlin, 1979; Crossin et al., 1998), and it has been proposed that behavioral thermoregulation may allow members of the species to occupy thermal niches which maximize their metabolic or behavioral efficiency. The behavioral responses of lobsters to thermal gradients suggest they have some mechanism to sense temperature so that they may effectively respond to the thermal properties of their environment.

Thermosensitivity in lobsters may be mediated by distinct thermoreceptors or thermosensitive neurons as in some other invertebrates (Prosser and Nelson, 1981; Mori and Ohshima, 1995). Although behavioral studies strongly suggest that $H$. americanus can sense temperature (Reynolds and Casterlin, 1979; Crossin et al., 1998), to our knowledge only one study has addressed how neurons respond to changes in temperature in this species. In that study, firing of cells associated with thoracic ganglia connectives generally showed no spontaneous activity below $14{ }^{\circ} \mathrm{C}$, but most became spontaneously active above this temperature. Interestingly, these cells "cycle reversibly from silent to continuously active to bursting and back as the temperature is 
increased and decreased" (Konishi and Kravitz, 1978). Other than these cells, which may or may not play a role in thermally guided behaviors, we know little about the location of putative thermoreceptors, or the mechanisms used to detect temperature, in lobsters and most other crustaceans (Dorai Raj and Murray, 1962; Ache, 1982).

In situations where the precise receptors have not been identified, or are not readily accessible to electrophysiological investigation, cardiac assays are a valuable tool for preliminary investigations of sensory capabilities (Larimer, 1964; Offutt, 1970; Florey and Kriebel, 1974; Dufort, 1997). For example, many crustaceans exhibit a drop in heart rate in response to novel stimuli (Maynard, 1960; Larimer, 1964; McMahon and Wilkens, 1972; DeWachter and McMahon, 1996). This cardiac response has been used to measure the ability of $H$. americanus to detect sound (Offutt, 1970) and salinity (Dufort, 1997). Although a number of studies have addressed the effect of temperature on decapod heart rates at time scales ranging from hours to days (Ahsanullah and Newell, 1971; Florey and Kriebel, 1974; DeFur and Magnum, 1979; DeWachter and McMahon, 1996; DeWachter and Wilkens, 1996; Hokkanen and Demont, 1997), few have characterized the initial response (i.e., $<5 \mathrm{~min}$.) to brief changes in water temperature. The present study used a cardiac assay to demonstrate that American lobsters are consistently capable of sensing increases or decreases in temperature that are greater than 1 ${ }^{\circ} \mathrm{C}$. The typical response elicited by both cold and warm stimuli was a brief slowing of the heart rate, followed by prolonged cardioacceleration. Winter and summer lobsters responded somewhat differently to thermal stimuli, suggesting some type of seasonal temperature-independent modulation of their responsiveness to thermal stimuli.

\section{Materials and Methods}

\section{Animals}

Adult (82-92 mm carapace length), intermolt lobsters were held at $15 \pm 1{ }^{\circ} \mathrm{C}$ (salinity $30 \pm 1 \mathrm{ppt}$ ) for more than 4 weeks prior to use, and experiments were initiated at this temperature. All lobsters were captured from coastal New Hampshire waters, and experiments were conducted at the University of New Hampshire, Durham, New Hampshire. Experiments were carried out in both summer and winter under ambient light conditions. In the summer, the thermosensitivity of 18 lobsters was determined (cold stimuli, $n=$ 9; warm stimuli, $n=9$ ); in the winter, lobsters kept at the same temperature $\left(15^{\circ} \mathrm{C}\right)$ as summer lobsters were used in identical experiments (cold stimuli, $n=8$; warm stimuli, $n$ $=10$ ).

\section{Recording of temperature and heart activity}

Small wire electrodes were inserted through the dorsal carapace above the heart and used with a UFI impedance converter (model \#2991) to record heart rate (Dyer and Uglow, 1970). Because the impedance recording technique can be sensitive to temperature, the method was verified by using a second pair of electrodes and a Grass model 7D polygraph to simultaneously monitor the electrical activity associated with lobster heart contractions (see Watson and Wyse, 1978; Watson, 1980). External temperature was recorded using a small $(3 \mathrm{~mm} \times 1 \mathrm{~mm})$ thermistor $(\mathrm{C} \& \mathrm{~B}$ Sciences/iWorx, Inc., Dover, NH) placed on the dorsal carapace. The thermistor was calibrated weekly over the range of temperatures used in the experiments. The time constant of the thermistor was $2.0 \mathrm{~s}$ (time to achieve $67 \%$ of the final response). The absolute resolution of the thermistor was $\pm 0.15{ }^{\circ} \mathrm{C}$, but it could accurately detect changes in temperature as small as $0.01{ }^{\circ} \mathrm{C}$. However, because of turbulent mixing within the recording chamber, the slight time delay due to the time constant of the thermistor (Fig. 1), and the unknown location of temperature-sensitive neural elements relative to the location of the thermistor, it was not possible to assess the thermal detection threshold with great accuracy. All temperatures presented are those recorded by the externally located thermistor above the dorsal carapace. These should be interpreted conservatively, in the context of the methods used and the unknown location of the sensory receptors.

\section{Experimental chamber}

After insertion of the electrodes, lobsters were placed in a recording chamber consisting of an 18-cm-diameter PVC pipe covered on the top and bottom by perforated plates through which seawater (temperature $15 \pm 1{ }^{\circ} \mathrm{C}$ ) continuously flowed (Fig. 1). This arrangement kept lobsters relatively immobile and ensured that changes in temperature within the recording chamber were rapid and relatively homogeneous. The chamber was placed in an acrylic plastic insert $(30 \times 30 \times 30 \mathrm{~cm})$ that was immersed in a temperature-controlled 120-1 aquarium (the ambient bath). Ambient seawater was continuously pumped $(2 \mathrm{l} / \mathrm{min})$ from the aquarium through the recording chamber, into the insert, and back to the aquarium. Thermal stimuli were delivered by switching the source of seawater from the ambient bath to the stimulus bath. This switching was accomplished by turning a stopcock and was considered the initiation of the stimulus (see arrows in Fig. 2). The stimulus bath was filled from the ambient bath to minimize novel chamber chemosensory cues (Fig. 1) and brought to the appropriate experimental temperature using aquarium heaters or cooling coils. The recording chamber was covered with black plastic to minimize visual disturbance, and the lobster was left in the experimental apparatus overnight before an experiment. Lobsters are much more sensitive to stimuli if allowed to recover from electrode insertion and become accustomed to the recording chamber (Larimer, 1964; Dufort, 1997). 
A.
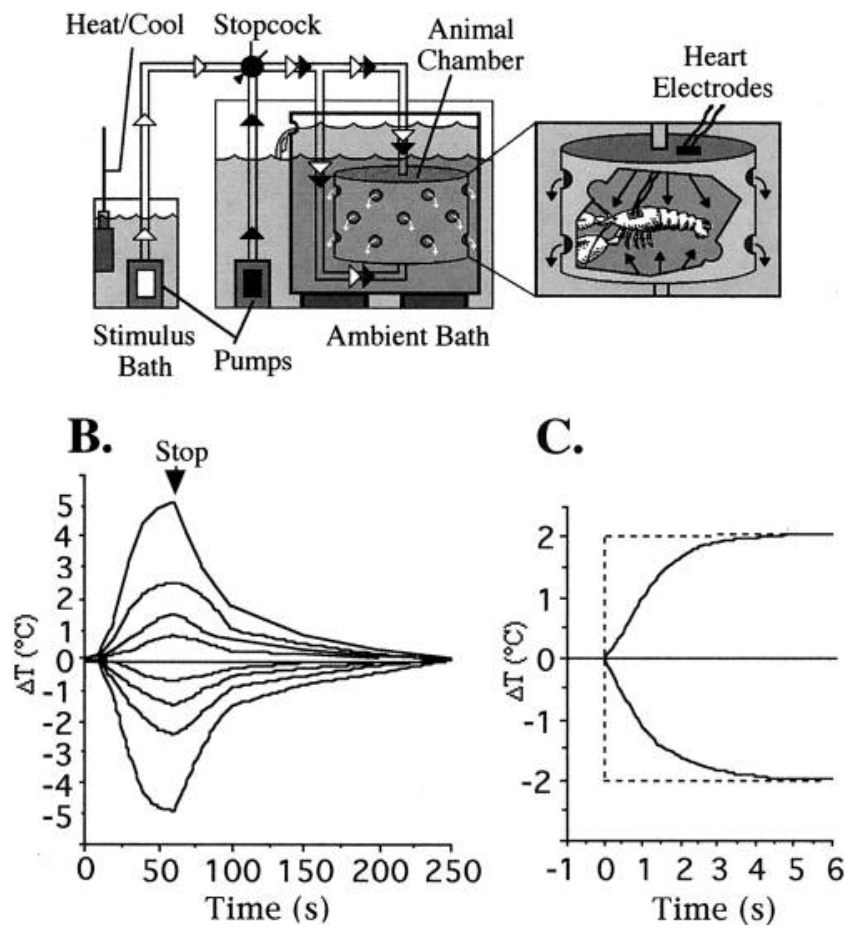

Figure 1. Experimental apparatus used to record lobster cardiac responses to changes in temperature. (A) Seawater $\left(15^{\circ} \mathrm{C}\right)$ flows continuously from the ambient bath into the animal chamber through perforated plates located above and below the lobster (direction of flow indicated by dark arrows). Heart rate is recorded before, during, and after exposure to a temperature stimulus. Switching the stopcock changes the source of seawater from the ambient bath to seawater from the stimulus bath (direction of flow indicated by white arrows). A thermistor on the dorsal carapace is used to monitor temperature during each trial. (B) Rates of temperature change in a typical experiment in response to $1 \mathrm{~min}$ stimuli (turned on at time $=0$ and off at arrow) of $\pm 0.7,1.4,2.6$, and $5.0^{\circ} \mathrm{C}$ warmer or colder than the ambient temperature. (C) Time constant of the thermistor when exposed to a step change in temperature of $\pm 2{ }^{\circ} \mathrm{C}$ (dotted line). The estimated time to achieve $67 \%$ of final temperature is $2.0 \mathrm{~s}$.

The following day, after basal heart rate was measured for at least $30 \mathrm{~min}$, each animal was exposed for $1 \mathrm{~min}$ to a warm or cold stimulus that changed the temperature in the recording chamber at a rate of $\pm 0.7{ }^{\circ} \mathrm{C} / \mathrm{min}$. This was followed by stimuli delivered at targeted rates of \pm 1.5 ${ }^{\circ} \mathrm{C} / \mathrm{min}, \pm 2.5{ }^{\circ} \mathrm{C} / \mathrm{min}$, and $\pm 5.0{ }^{\circ} \mathrm{C} / \mathrm{min}$ for $1 \mathrm{~min}$. Temperature was allowed to return to ambient (Fig. 2) between each treatment. Treatments were separated by at least 30 min. The temperature in the recording chamber was monitored with the dorsally located thermistor, and the actual mean rates achieved were $0.72 \pm 0.04,1.37 \pm 0.06,2.61 \pm$ 0.10 , and $4.95 \pm 0.16^{\circ} \mathrm{C} / \mathrm{min}$. Thus, the average maximum warm stimuli after $60 \mathrm{~s}$ were $15.7,16.4,17.6$, and $20.0^{\circ} \mathrm{C}$, and the maximum cold stimuli were 14.3, 13.6, 12.4, and $10.0{ }^{\circ} \mathrm{C}$.

Which stimulus (warm or cold) was tested on the first day was assigned randomly, and the other set of stimuli (warm or cold) were tested on the following day. A $25 \%$ change in heart rate-bradycardia (decrease) or tachycardia (increase) - was used as an indicator that lobsters sensed a change in water temperature (Offutt, 1970; Dufort, 1997). All records were digitized using a MacLab system (C \& B Sciences/iWorx, Inc.) and were analyzed to determine the following: (1) delay to a response; (2) duration of bradycardia, tachycardia, or both; (3) heart rate (bpm) during bradycardia; and (4) heart rate (bpm) during tachycardia. In addition, thermosensitivity thresholds were estimated from the water temperature measured above the dorsal carapace at the time of the initial cardiac response. Controls were conducted before any thermal stimuli were applied; the same protocol described above was followed, but without changing the temperature in the stimulus bath.

\section{Localization of putative temperature receptors}

In an attempt to localize regions with putative temperature receptors, lobsters missing antennae $(n=4)$ or missing antennae and antennules $(n=4)$ were tested for a response to a temperature change of $+2.5^{\circ} \mathrm{C} / \mathrm{min}$. Antennae or antennules were removed bilaterally at their base, the wounds were sealed with wax to prevent blood loss, and the lobsters were allowed more than $24 \mathrm{~h}$ to recover.

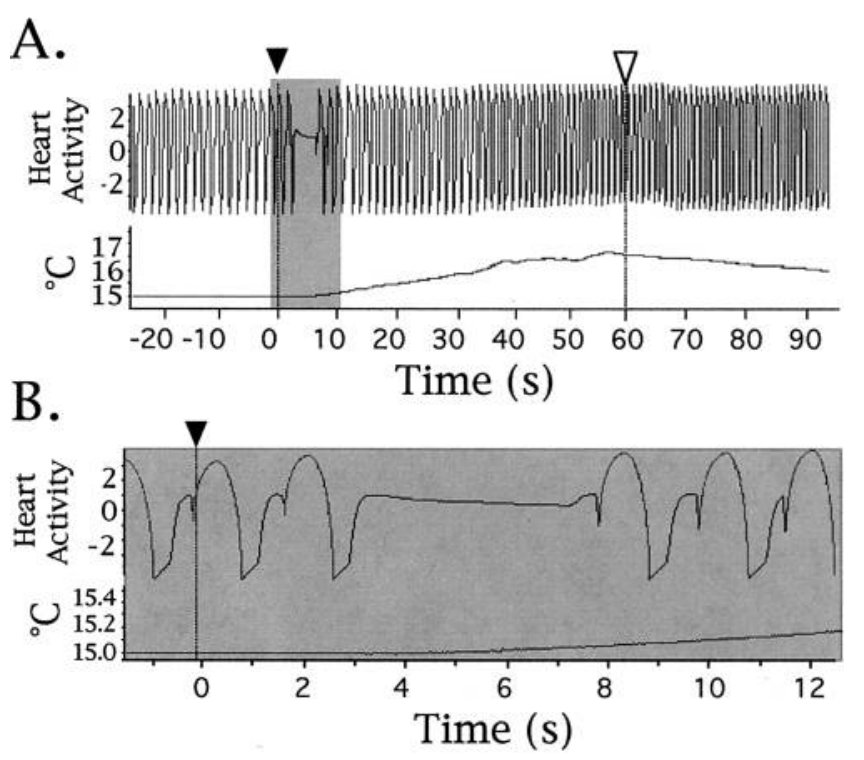

Figure 2. Typical cardiac response to a change in temperature. (A) The top trace shows the typical response to a $+1.4{ }^{\circ} \mathrm{C} / \mathrm{min}$ stimulus; the lower trace is a plot of the temperature change during the 60 -s trial. The dark closed arrow shows when the stimulus flow was turned on, and the white open arrow shows when it was turned off. (B) An enlargement of the highlighted area from (A), showing the time course of the bradycardia and associated temperature change. Note that the rapid response may be a result of the combination of the location of the thermistor relative to the location of the unknown temperature sensitive receptors and the slight delay due to the time constant of the thermistor. There was no response to controls when the flow was switched but the temperature was not changed. 
To determine whether changes in cardiac activity were mediated by the cardioregulatory nerves, responses to thermal stimuli were measured before and after nerve lesions ( $n$ $=5$ ). Changes in heart rate were initially recorded in response to thermal stimuli of $+1.5{ }^{\circ} \mathrm{C} / \mathrm{min}$ and $-1.5{ }^{\circ} \mathrm{C} /$ $\min$. Then the cardioregulatory nerves were cut, and lobsters were allowed at least 2 days to recover. Finally their cardiac responses were measured again in response to the same stimuli that were applied before the lesions. Lesions were made as described in Guirguis and Wilkens (1995). A small $\left(3-\mathrm{cm}^{2}\right)$ rectangular piece of dorsal carapace just above the heart was removed, and superficial cuts were made with fine scissors through the connective tissue along the border of the opening. The shell was then replaced and fastened in place with tape. Sham-operated control animals $(n=4)$ were treated in the same manner except that no cuts were made in the connective tissue.

\section{Statistical analysis}

Throughout the text, variation is presented as standard error of the mean (i.e., mean \pm SEM). A $P$ value of $<0.05$ was considered to be significant for all statistical tests.

\section{Results}

\section{Typical response to a change in temperature}

The typical cardiac response to both warm and cold stimuli consisted of a short bradycardia $(39.5 \pm 8.0 \mathrm{~s})$, followed by a significantly (paired $t$ test) longer tachycardia $(188.2 \pm 10.7 \mathrm{~s} ;$ Fig. 2$)$. In general, changes in heart activity were similar in response to both warm $(n=19)$ and cold $(n$ $=17$ ) stimuli. Although the intensity and duration of cardiac responses were similar for all temperatures tested (ANOVA, $P>0.05$ ), some lobsters did not respond to slower rates of change $\left(0.7\right.$ and $\left.1.4^{\circ} \mathrm{C} / \mathrm{min}\right)$, whereas almost all lobsters responded to the maximum rate of change (5.0 ${ }^{\circ} \mathrm{C} / \mathrm{min}$; Fig. 3). There was no cardiac response in control trials $(n=36)$, where temperature was not changed but ambient water was pumped through the chamber from the stimulus bath (Fig. 4).

\section{Sensitivity to warm and cold stimuli}

Lobsters were extremely sensitive to both warm and cold stimuli (Fig. 3). For example, when subjected to a $+2.6{ }^{\circ} \mathrm{C} / \mathrm{min}$ stimulus, lobsters responded after just $3.8 \pm 0.5 \mathrm{~s}$, when the temperature in the chamber had changed by only $0.09 \pm 0.04{ }^{\circ} \mathrm{C}$. Lobsters exposed to the $-2.6^{\circ} \mathrm{C} / \mathrm{min}$ stimulus responded after a drop of only $0.13 \pm 0.09{ }^{\circ} \mathrm{C}$, and the latency to respond $(4.6 \pm 1.8 \mathrm{~s})$ was not significantly different (paired $t$ test) than during a warm stimulus (Fig. 3).

Temperature change measured at the initiation of a cardiac response by individual lobsters ranged from 0.01

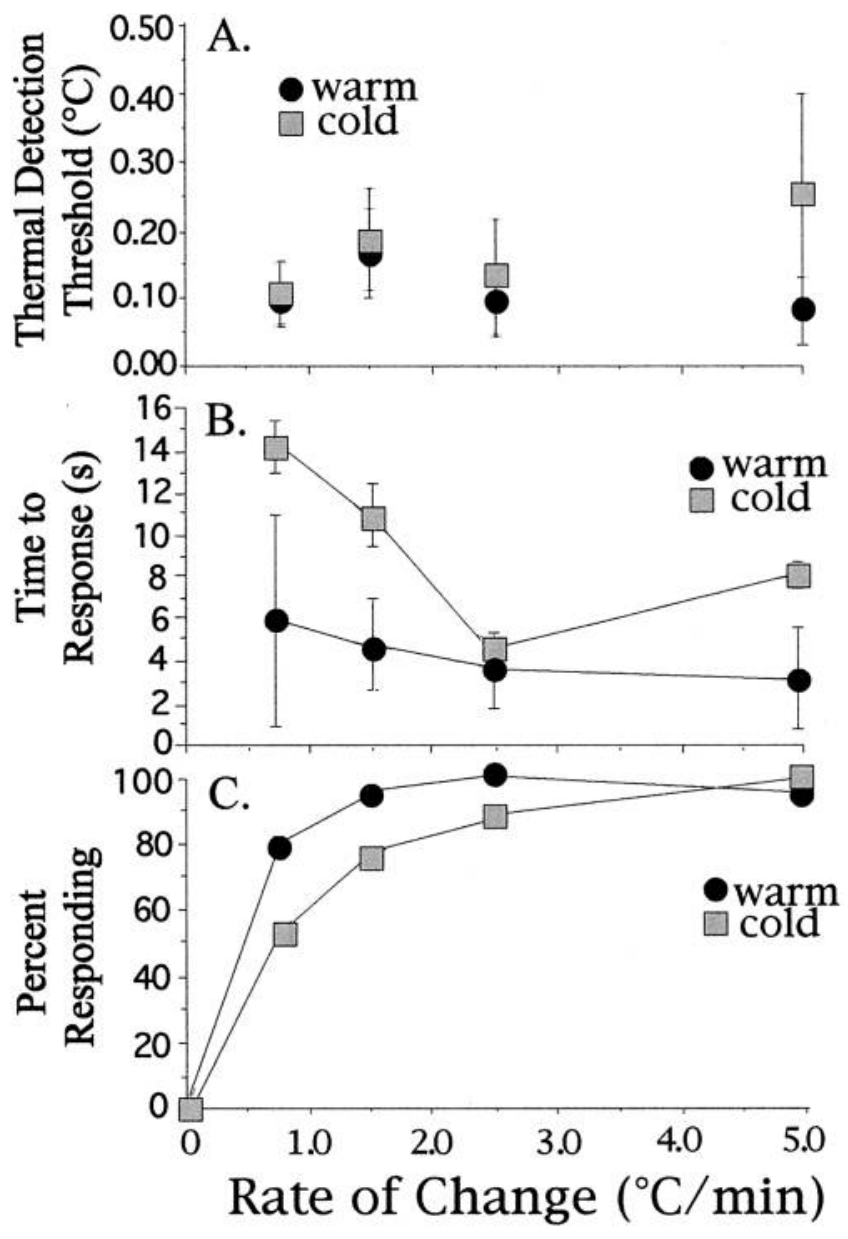

Figure 3. Responses to thermal stimuli at different rates of change. (A) The thermal detection threshold, or the amount of temperature change required to elicit a cardiac response, was similar even when hot and cold stimuli were applied at different rates. (B) When thermal stimuli were applied at slow rates of change, the delay to respond was longer, especially in the case of cold stimuli. (C) Although lobsters responded similarly to thermal stimuli applied at fast and slow rates of change, some animals did not respond at all to slow rates of change, while all animals responded to higher rates of change.

to $0.79{ }^{\circ} \mathrm{C}$. There were no significant differences (unpaired $t$ test) between the sexes in the temperature change at initial response; when lobsters responded, they exhibited comparable thresholds, at all measured rates of change (Fig. 3, Kruskal-Wallis test). The average temperature-detection threshold, for all trials in which animals responded, was $0.15 \pm 0.03{ }^{\circ} \mathrm{C}$. This is considered to be only an estimate because of the inherent time constant and resolution of the thermistor, the flow of water in the chamber, and the location of the thermistor relative to the still unknown location of the receptors mediating the response. Nonetheless, this assay demonstrates that lobsters are sensitive to very small changes in temperature. 

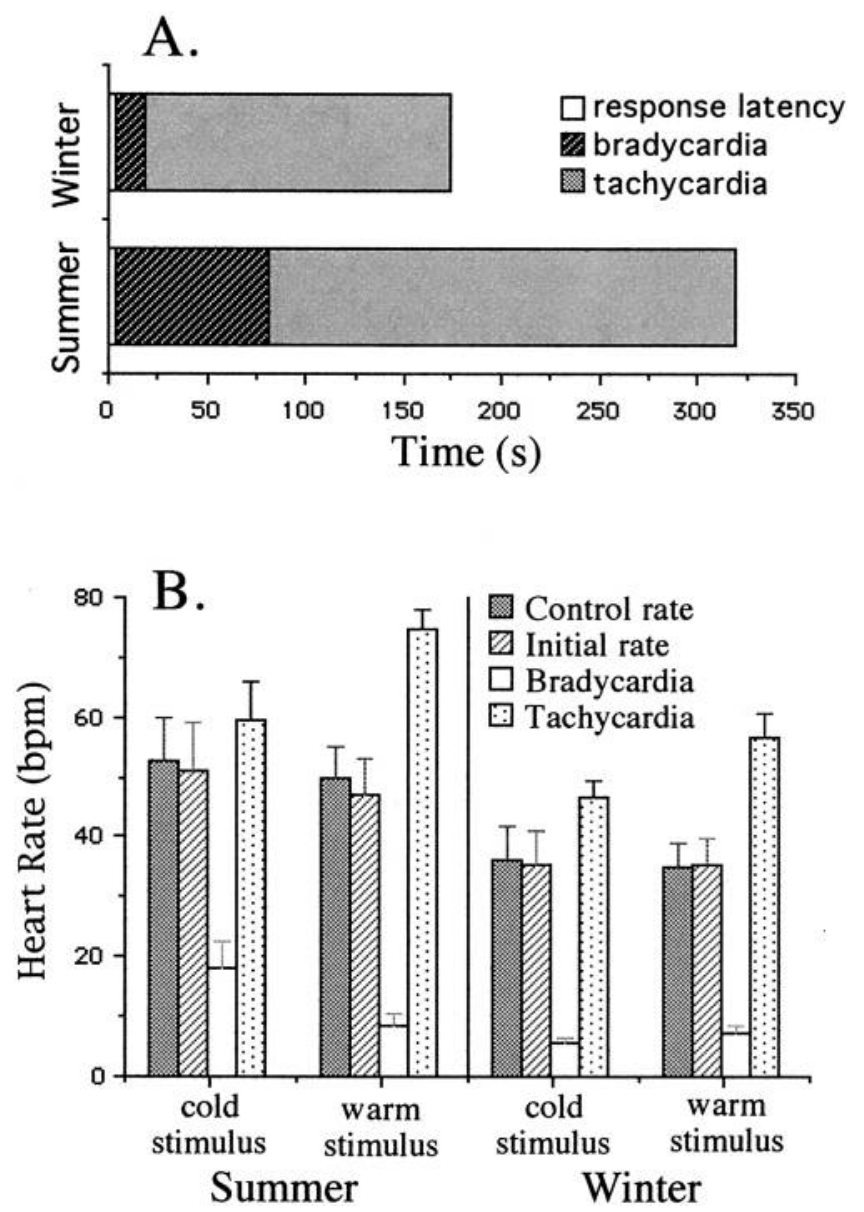

Figure 4. Responses to cold and warm stimuli by summer and winter animals. (A) The mean response latency, duration of bradycardia, and duration of tachycardia in response to $\pm 2.6{ }^{\circ} \mathrm{C} / \mathrm{min}$ stimuli in both summer and winter lobsters. While the latency to respond, and thus thresholds, were similar between seasons, the duration of both bradycardia and tachycardia responses tended to be longer in summer animals. (B) Differences in the responsiveness of summer and winter lobsters. For all treatments, an application of control $15{ }^{\circ} \mathrm{C}$ stimuli to lobsters held at $15{ }^{\circ} \mathrm{C}$ did not cause a statistically significant change in heart rate. Lobsters in both seasons responded to $\pm 2.6{ }^{\circ} \mathrm{C} / \mathrm{min}$ stimuli with a short bradycardia followed by a longer tachycardia. The major difference between summer and winter lobsters, other than the duration of responses shown in A, was that animals in the winter had significantly lower initial heart rates. Thus, although all animals were held at $15^{\circ} \mathrm{C}$, there appears to be some temperature-independent seasonal modulation of heart rate.

\section{Localization of receptors}

All lobsters with ablated antennae $(n=4)$ or ablated antennae and antennules $(n=4)$ showed typical responses to a stimulus of $+2.5{ }^{\circ} \mathrm{C} / \mathrm{min}$. There was no significant difference (unpaired $t$ tests) in the duration of bradycardia and tachycardia, the thermosensitivity threshold, or the baseline heart rate when compared to intact lobsters $(n=$ 18).

Prior to cardioregulatory nerve lesions, lobsters $(n=5)$ had a mean heart rate of $41 \pm 2.9 \mathrm{bpm}$. Following recovery, their heart rate increased to $70 \pm 5.3 \mathrm{bpm}$, which was significantly higher (paired $t$ test) than the basal rate. This increase may not have been due solely to the lesion of the cardioregulatory nerves: sham-operated controls $(n=4)$ also had heart rates $(48 \pm 9.4 \mathrm{bpm})$ that were slightly higher than their pre-operation baselines ( $37 \pm 5.4 \mathrm{bpm}$ ), although that difference was not significant (paired $t$ test). In response to a hot or cold stimulus, all lobsters exhibited typical bradycardia and tachycardia responses before cardioregulatory nerve lesioning. However, after lesioning none of the lobsters showed an increase or decrease in heart rate in response to thermal stimuli. In contrast, all of the shamoperated lobsters showed typical responses (100\% showed both bradycardia and tachycardia) when exposed to identical thermal stimuli. These data indicate that the change in heart rate elicited by warm and cold stimuli is mediated by the cardioregulatory nerves and not by the direct influence of temperature on the heart itself.

\section{The influence of season}

The characteristic cardiac response of lobsters to a change in temperature (a short bradycardia followed by a longer tachycardia) was similar for lobsters tested in the winter and those tested in the summer. However, the following differences were apparent: (1) the mean baseline heart rate was significantly lower (unpaired $t$ test) in winter lobsters $(34.8 \pm 4.4 \mathrm{bpm})$ than in summer lobsters $(49.9 \pm$ 5.0 bpm; Fig. 4); (2) the duration of bradycardia and tachycardia responses tended to be shorter in the winter lobsters (unpaired $t$ tests, $P<0.1$ ); and (3) winter lobsters tended to respond to temperature changes with both tachycardia $(83 \%)$ and bradycardia (72\%), whereas only $50 \%$ of the summer lobsters responded with tachycardia, but $94 \%$ showed bradycardia. Thus, even though winter and summer lobsters were both held at $15{ }^{\circ} \mathrm{C}$ for at least one month and tested with identical warm and cold stimuli, they responded differently. This difference may be related to the observed seasonal differences in basal physiological state (Fig. 4).

\section{Discussion}

This study supports the findings of two previous behavioral studies which infer that American lobsters can sense changes in temperature (Reynolds and Casterlin, 1979; Crossin et al., 1998). Assuming that the initiation of a cardiac response indicates detection of an environmental change, our conservative estimate is that lobsters can sense both increases and decreases in water temperature of greater than $1{ }^{\circ} \mathrm{C}$ (Fig. 3) and probably as small as $0.15^{\circ} \mathrm{C}$. Similar thermal sensitivity has been documented in a number of terrestrial arthropods (Murphy and Heath, 1983; Altner and Loftus, 1985). For example, the spider Cupiennus salei has a warm receptor with a detection threshold between 0.08 
and $0.6{ }^{\circ} \mathrm{C}$ (Ehn and Tichy, 1996). Studies of thermoreception in aquatic species are fewer, but are consistent with our findings. For example, Forward (1990) found that crab larvae (Rhithropanopeus harrisii and Neopanope sayi) ascend or descend in a water column in response to absolute temperature changes of $0.29-0.49^{\circ} \mathrm{C}$, as long as the rate of change is fast enough $\left(0.06-0.24{ }^{\circ} \mathrm{C} / \mathrm{min}\right.$, depending on larval stage and species). Thus, the American lobster is probably not unusual in its ability to detect small changes in temperature, although the extent to which this level of thermosensitivity exists in other crustaceans remains to be investigated.

Although several behavioral studies indicate that crustaceans are quite sensitive to changes in temperature, little is known about thermosensitivity in this large group of primarily aquatic invertebrates. A study of the thermal sensitivity of the dactyl receptors of Cancer antennarius, $C$. anthonyi, and Panulirus interruptus strongly suggests that they possess a thermal sensory system capable of integrating temperature information for use in thermally cued behavior (Cook, 1984). However, the actual thermoreceptors have not been identified in these species. In lobsters, a number of neurons change their rate of firing in response to shifts in temperature, but it is not clear if these cells are actually serving the function of thermoreceptors. For example, intracellular recordings from cells of the thoracic ganglia connectives of $H$. americanus show firing patterns that reversibly change from silent to continuously active to bursting over the range of $10-17{ }^{\circ} \mathrm{C}$ (Konishi and Kravitz, 1978). This is within the normal ecological range for this species, and while it is unknown what physiological or motor output results from this neuronal property, the correspondence to the behaviorally determined preferred temperature $\left(16^{\circ} \mathrm{C}\right.$; Crossin et al., 1998) for this species is intriguing. In the spiny lobster, Panulirus japonicus, ligamental nerves innervating the pericardial organ have also been reported to increase their firing in response to cold stimulation (Kuramoto and Tani, 1994). Once again, temperature stimuli were shown to have a direct physiological effect in vitro, but it is unknown how, or if, this effect is related to the existence of thermoreceptors or behavioral thermoregulation. Ablation studies indicate that lobsters missing antennae or antennules respond to temperature just like intact animals, suggesting that while these appendages may or may not contain thermosensitive elements, they are not necessary in order for lobsters to exhibit a cardiac response to temperature. Thus, while localization of receptors and mechanisms of thermoreception are beginning to be elucidated in some invertebrates (Mori and Ohshima, 1995; Komatsu et al., 1996; McCleskey, 1997), it remains unclear exactly where and how crustaceans are sensing temperature (Ache, 1982).

Although gradual changes in temperature have a profound, well-documented influence on the metabolism and cardiovascular function of lobsters (Mercaldo-Allen and Thurberg, 1987; McMahon, 1995; Whiteley et al., 1995; DeWachter and McMahon, 1996), brief decreases in heart rate following acute temperature changes are also common in lobsters and many crustaceans (McMahon and Wilkens, 1972; McMahon, 1995; DeWachter and McMahon, 1996). It is unlikely that these acute responses are due to a direct impact of temperature on the heart for the following reasons: (1) lobsters with cut cardioregulatory nerves do not change their heart rate in response to acute temperature changes; (2) $\mathrm{Q}_{10}$ values for heart rates of intact lobsters generally range from 1.5 to 2.5 (Mercaldo-Allen and Thurberg, 1987; Schreiber et al., 1998), but excised lobster hearts are not very sensitive to changes in temperature over the range of 12 to $19^{\circ} \mathrm{C}$, and they generally have lower $\mathrm{Q}_{10}$ values than intact lobsters over the same range (Schreiber $e t$ al., 1998; Jury, unpublished data); (3) the initiation of a cardiac response is immediate and robust, and the response extends well beyond the duration of a temperature stimulus (Fig. 2); and (4) the response is similar (i.e., bradycardia followed by tachycardia) whether warm or cool stimuli are applied (Fig. 3). Therefore, although temperature can have a long-term, direct influence on heart rate and cause release of modulatory substances from the pericardial organs of lobsters (Kuramoto and Tani, 1994), all current data strongly suggest that in lobsters some type of thermosensitive mechanism senses a change in temperature, and this leads to a change in heart rate through activation of inhibitory or excitatory cardioregulatory nerves.

Lobsters do not appear to have seasonal differences in their ability to detect temperature. However, winter lobsters have lower basal heart rates and respond to temperature somewhat differently than summer lobsters. These differences suggest the presence of some type of seasonal modulation of the lobster cardiovascular system, similar to the actions of thyroid hormones in frogs (Miller and Mizell, 1972). Biogenic amines, such as serotonin and octopamine, have been shown to increase cardiac output. Seasonal changes in circulating levels of these, or similar, neuromodulators might increase basal heart rates in the summer or alter how the heart responds to input from cardioregulatory nerves (Fingerman et al., 1994; Wood et al., 1995; Weiger, 1997). This type of seasonal modulation is likely to influence responses to a variety of stimuli, in addition to temperature. The precise mechanisms underlying these seasonal changes in the cardiovascular system of crustaceans remain to be resolved. A recent study of blue crabs, Callinectes sapidus, which documented seasonal differences in their behavioral responses to injected biogenic amines and proctolin (Wood et al., 1995), suggests that seasonal variability in the expression of receptors may be the mechanism.

The rate of temperature change may be an important variable in detection of thermal shifts in the environment. The lobsters in this study responded to rates as low as 0.7 
${ }^{\circ} \mathrm{C} / \mathrm{min}$, and there was no statistically significant difference between the thermal-detection thresholds obtained over the range of rates tested. We did not attempt to determine the slowest rate of change they were able to detect, but we did find that some lobsters did not respond at all to the slower rates of change used in our experiments $\left(0.7-1.4{ }^{\circ} \mathrm{C} / \mathrm{min}\right)$. Florey and Kriebel (1974) found that in Cancer species, the rate of change must be greater than $0.33{ }^{\circ} \mathrm{C} / \mathrm{min}$ to "avoid hysteresis effects." This is interpreted as meaning that acute bradycardias or tachycardias were seen at rates of change faster than this, but only long-term changes in heart rate were observed at slower rates. Crab larvae ( $R$. harrisii) descend in the water column when the temperature is elevated at rates ranging from 0.07 to $0.24{ }^{\circ} \mathrm{C} / \mathrm{min}$, and they ascend when the temperature decreases at rates of 0.06 to $0.1{ }^{\circ} \mathrm{C} / \mathrm{min}$. However, "the average absolute amounts of temperature change needed to evoke a response was independent of the rate of change at rates above threshold and ranged from 0.29 to $0.49{ }^{\circ} \mathrm{C}$ " (Forward, 1990). Seasonal changes in water temperature in some lobster habitats (e.g., coastal New Hampshire) can range from 0 to $25^{\circ} \mathrm{C}$, but rates of change may be too slow to directly stimulate putative lobster thermoreceptors. However, tidal changes or thermoclines may change fast enough to be detected. We have measured rates of temperature change as high as 0.33 ${ }^{\circ} \mathrm{C} / \mathrm{min}$ in the Great Bay estuary, although average rates are about $0.004{ }^{\circ} \mathrm{C} / \mathrm{min}$ (based upon hourly Licor CTD readings, R. Langan, University of New Hampshire, Durham, unpublished data). Some studies have also found lobsters to aggregate at thermoclines (Ennis, 1984; Estrella and Morrissey, 1997). Movement of a lobster (or an appendage) within a thermally heterogeneous habitat may increase the realized rate of change to the point at which temperatures fall within the detection range. In addition, movement of water (i.e., a current) past a stationary or moving lobster could also increase the rate of change if the water was thermally heterogeneous. Thus, under appropriate conditions, the combination of mobility and sensitivity to small temperature changes may provide lobsters with sufficient information to behaviorally thermoregulate in their natural habitat in the same manner observed in small thermal gradient tanks (Crossin et al., 1998). Nonetheless, although lobsters can apparently use temperature as a cue in habitat selection (Reynolds and Casterlin, 1979; Crossin et al., 1998), the neural mechanisms giving rise to thermally guided movements are unknown.

In this study we used changes in heart rate to determine the sensitivity of lobsters to thermal stimuli. While this assay is useful for determining an animal's ability to sense small changes in temperature, it is not known whether lobsters exhibit similar changes in heart rate when they encounter thermal shifts in their natural habitat. Crustaceans held for more than $12 \mathrm{~h}$ in a state of "sensory deprivation" have been reported to be much more responsive to a variety of environmental stimuli (Offutt, 1970; Florey and Kriebel, 1974); thus, the sensitivity of lobsters to temperature may have been enhanced in our experiments. In contrast, lobsters that are not given time to recover from handling have high basal heart rates and often do not exhibit typical responses to environmental stimuli. Thus, although lobsters in their natural habitat can probably sense very small changes in water temperature, these thermal stimuli may not always lead to the types of cardiac responses observed in quiescent laboratory animals. This hypothesis is being tested by recording from freely moving lobsters subjected to acute changes in temperature as they move spontaneously through thermal gradients.

\section{Acknowledgments}

We thank the following people for helping to make this project possible: Heather Jury, Chris Dufort, Jim Newcomb, Paul Bartell, Christina Rockel, and Glen Crossin. Special thanks to Dan O'Grady for conducting the cardioregulatory nerve lesion experiments; Hunt Howell at the UNH Coastal Marine Lab for supplying animals; Rich Langan at the UNH Jackson Estuarine Lab for housing animals; Dan Reves for drawings; and Cliff Bredneberg and Ashish More of C \& B Sciences, Inc., for technical assistance. This work was supported by USDA (Hatch) and NOAA (Sea Grant) grants to WHW and by UNH Graduate student enhancement and Center for Marine Biology Grants to SHJ. This study was part of the doctoral dissertation research of SHJ. This manuscript was greatly improved by the comments of three anonymous reviewers. This is contribution \#355 of the UNH Center for Marine Biology Series.

\section{Literature Cited}

Ache, B. W. 1982. Chemoreception and thermoreception. Chapter 8, pp. 390-391, in D. Bliss, ed., The Biology of Crustacea. Neurobiology: Structure and Function, Vol. 3. Academic Press, New York.

Ahsanullah, M., and R. C. Newell. 1971. Factors affecting the heart rate of the shore crab Carcinus maenas (L.). Comp. Biochem. Physiol. 39A: 277-287.

Aiken, D. E., and S. L. Waddy. 1986. Environmental influence on recruitment of the American lobster, Homarus americanus: a perspective. Can. J. Fish. Aquat. Sci. 43(11): 2258-2270.

Altner, H., and R. Loftus. 1985. Ultrastructure and function of insect thermo- and hygroreceptors. Annu. Rev. Entomol. 30: 273-295.

Cobb, J. S., and B. F. Phillips. 1980. The Biology and Management of Lobsters, Vol. 1. Physiology and Behavior. Academic Press, New York.

Cook, D. P. 1984. Chemoreception, thermoreception and osmoreception in three marine decapod crustaceans. Ph.D. dissertation. University of California, Santa Barbara. 140 pp.

Cooper, R. A., and J. R. Uzmann. 1971. Migrations and growth of deep-sea lobsters, Homarus americanus. Science 171: 288-290.

Crossin, G., S. A. Al-Ayoub, S. H. Jury, W. H. Howell, and W. H. Watson III. 1998. Behavioral thermoregulation in the American lobster (Homarus americanus). J. Exp. Biol. 201: 365-374.

deFur, P. L., and C. P. Magnum. 1979. The effects of environmental 
variables on the heart rates of invertebrates. Comp. Biochem. Physiol. 62A: 283-294.

DeWachter, B., and B. R. McMahon. 1996. Temperature effects on heart performance and regional hemolymph flow in the crab, Cancer magister. Comp. Biochem. Physiol. 114A(1): 27-33.

DeWachter, B., and J. L. Wilkens. 1996. Comparison of temperature effects on heart performance of the Dungeness crab, Cancer magister, in vitro and in vivo. Biol. Bull. 190: 385-395.

Dorai Raj, B. S., and R. W. Murray. 1962. Non-myelinated nerves as a model for thermoreceptors. Comp. Biochem. Phvsiol. 5: 311-317.

Dufort, C. 1997. Detection of salinity by the American lobster, Homarus americanus. M.S. Thesis. University of New Hampshire, Durham.

Dyer, M. F., and R. F. Uglow. 1970. On a technique for monitoring heart and scaphognathite activity in Natantia. J. Exp. Mar. Biol. Ecol. 27: $117-124$

Ehn, R., and H. Tichy. 1996. Response characteristics of a spider warm cell: temperature sensitivities and structural properties. J. Comp. Physiol. A 178: 537-542.

Ennis, G. P. 1984. Small-scale seasonal movements of the American lobster Homarus americanus. Trans. Am. Fish. Soc. 113: 336-338.

Estrella, B. T., and T. D. Morrissey. 1997. Seasonal movement of offshore American lobster, Homarus americanus, tagged along the eastern shore of Cape Cod, Massachusetts. Fish. Bull. 95: 466-476.

Factor, J. R. (ed.). 1995. Biology of the Lobster Homarus americanus. Academic Press, San Diego, CA.

Fingerman, M., R. Nagabhushanam, R. Sarojini, and P. S. Reddy. 1994. Biogenic amines in crustaceans: identification, localization, and roles. J. Crustac. Biol. 14: 413-437.

Florey, E., and M. E. Kriebel. 1974. The effects of temperature, anoxia and sensory stimulation on the heart rate of unrestrained crabs. Comp. Biochem. Physiol. 48A: 285-300.

Forward, R. B. 1990. Behavioral responses of crustacean larvae to rates of temperature change. Biol. Bull. 178: 195-204.

Guirgis, M. S., and J. L. Wilkens. 1995. The role of the cardioregulatory nerves in mediating heart rate responses to locomotion, reduced stroke volume and neurohormones in Homarus americanus. Biol. Bull. 188: $179-185$

Haakonsen, H. O., and A. O. Anoruo. 1994. Tagging and migration of the American lobster Homarus americanus. Rev. Fish. Sci. 2(1): 79 93.

Hokkanen, J. E. I., and M. E. DeMont. 1997. Complex dynamics in the heart of the lobster Homarus americanus. Can. J. Zool. 75: 746-754.

Karnofsky, E. B., J. Atema, and R. H. Elgin. 1989. Natural dynamics of population structure and habitat use of the lobster, Homarus americanus, in a shallow cove. Biol. Bull. 176: 247-256.

Komatsu, H., I. Mori, H-S. Rhee, N. Akaike, and Y. Ohshima. 1996. Mutations in a cyclic nucleotide-gated channel is required for sensory development and function in C. elegans. Neuron 17: 695-706.

Konishi, S., and E. A. Kravitz. 1978. The physiological properties of amine-containing neurones in the lobster nervous system. $\underline{\text { J. Physiol. }}$ 279: $215-229$

Kuramoto, T., and M. Tani. 1994. Cooling-induced activation of the pericardial organs of the spiny lobster, Panulirus japonicus. Biol. Bull. 186: $319-327$.

Larimer, J. L. 1964. Sensory induced modifications of ventilation and heart rate in crayfish. Comp. Biochem. Physiol. 12: 25-36.
Maynard, D. M. 1960. Circulation and heart function. Pp. 161-226 in The Physiology of Crustacea, Vol. 1. Academic Press, New York.

McCleskey, E. W. 1997. Thermoreceptors: recent heat in thermosensation. Curr. Biol. 7(11): 679-681.

McLeese, D. W., and D. G. Wilder. 1958. The activity and catchability of the lobster (Homarus americanus) in relation to temperature. J. Fish. Res. Board Can. 15: 1345-1354.

McMahon, B. R. 1995. The physiology of gas exchange, circulation, ion regulation, and nitrogenous excretion: an integrative approach. Pp. 497-517 in Biology of the Lobster Homarus americanus, J. R. Factor, ed. Academic Press. San Diego, CA.

McMahon, B. R., and J. L. Wilkens. 1972. Simultaneous apnoea and bradycardia in the lobster Homarus americanus. Can. J. Zool. 50: $165-170$

Mercaldo-Allen, R., and F. Thurberg. 1987. Heart and gill ventilatory activity in the lobster, Homarus americanus, at various temperatures. Fish. Bull. 85(3): 643-644.

Miller, L. C., and S. Mizell. 1972. Seasonal variation in heart rate response to core temperature changes. Comp. Biochem. Physiol. 42A: 773-779.

Mori, I., and Y. Ohshima. 1995. Neural regulation of thermotaxis in Caenorhabditis elegans. Nature 376: 344-348.

Murphy, B. F., and J. E. Heath. 1983. Temperature sensitivity in the prothoracic ganglion of the cockroach, Periplaneta americana, and its relationship to thermoregulation. J. Exp. Biol. 105: 305-315.

Offutt, G. C. 1970. Acoustic stimulus perception by the American lobster, Homarus americanus (Decapoda). Experientia 26: 1276-1278.

Pezzack, D. S., and D. R. Duggan. 1986. Evidence of migration and homing of lobsters (Homarus americanus) on the Scotian Shelf. Can. J. Fish. Aquat. Sci. 43: 2206-2211.

Prosser, C. L., and D. O. Nelson. 1981. The role of nervous systems in temperature adaptation of poikilotherms. Аnпи. Rev. Phvsiol. 43: 281 300 .

Reynolds, W. W., and M. E. Casterlin. 1979. Behavioral thermoregulation and activity in Homarus americanus. Comp. Biochem. Physiol. 64A: $25-28$.

Schreiber, S., S. Krull, S. H. Jury, and W. H. Watson. 1998. Effects of temperature on the heart rate and locomotion of the American lobster (Homarus americanus). Am. Zool. 37(5): 147A

Watson, W. H. 1980. Limulus polyphemus gill cleaning behavior. J. Comp. Physiol. 141: 67-75.

Watson, W. H., and G. A. Wyse. 1978. The coordination of heart and gill rhythms in Limulus polyphemus. J. Comp. Physiol. 124: 267-275.

Watson, W. H. III, A. Vetrovs, and W. H. Howell. 1999. Lobster movements in an estuary. Mar. Biol. 134: 65-75.

Weiger, W. A. 1997. Serotonergic modulation of behavior: a phylogenetic overview. Biol. Rev. 72: 61-95.

Whiteley, N. M., A. H. Al-Wassia, and E. W. Taylor. 1995. The effects of sudden changes in temperature on aquatic and aerial respiration in the lobster, Homarus gammarus (L.). Mar. Freshw. Behav. Phys. 27(1): 13-28.

Wood, D. E., R. A. Gleeson, and C. D. Derby. 1995. Modulation of behavior by biogenic amines and peptides in the blue crab, Callinectes sapidus. J. Comp. Physiol. A 177: 321-333. 